\title{
The Uncompetitive N-methyl-D-Aspartate Antagonist Memantine Reduces Binge-Like Eating, Food-Seeking Behavior, and Compulsive Eating: Role of the Nucleus Accumbens Shell
}

\author{
Karen L Smith', Rahul R Rao', Clara Velázquez-Sánchez', Marta Valenza', Chiara Giuliano², Barry J Everitt², \\ Valentina Sabino' and Pietro Cottone ${ }^{*, 1}$ \\ 'Laboratory of Addictive Disorders, Departments of Pharmacology and Psychiatry, Boston University School of Medicine, Boston, MA, USA; \\ ${ }^{2}$ Behavioral and Clinical Neuroscience Institute and Department of Psychology, University of Cambridge, Cambridge, UK
}

\begin{abstract}
Binge-eating disorder is characterized by excessive, uncontrollable consumption of palatable food within brief periods of time. The role of the glutamatergic N-methyl-D-aspartate (NMDA) receptor system in hedonic feeding is poorly understood. The aim of this study was to characterize the effects of the uncompetitive NMDA receptor antagonist memantine on palatable food-induced behavioral adaptations using a rat model, which mimics the characteristic symptomatology observed in binge-eating disorder. For this purpose, we allowed male Wistar rats to respond to obtain a highly palatable, sugary diet (Palatable group) or a regular chow diet (Chow control group), for I h a day, under a fixed-ratio I (FRI) schedule of reinforcement. Upon stabilization of food responding, we tested the effects of memantine on the Chow and Palatable food groups' intake. Then, we tested the effects of memantine on food-seeking behavior, under a second-order schedule of reinforcement. Furthermore, we investigated the effects of memantine on the intake of food when it was offered in an aversive, bright compartment of a light/dark conflict test. Finally, we evaluated the effects of memantine on FRI responding for food, when microinfused into the nucleus accumbens (NAcc) shell or core. Memantine dose-dependently decreased binge-like eating and fully blocked food-seeking behavior and compulsive eating, selectively in the Palatable food group. The drug treatment did not affect performance of the control Chow food group. Finally, intra-NAcc shell, but not core, microinfusion of memantine decreased binge-like eating. Together, these findings substantiate a role of memantine as a potential pharmacological treatment for binge-eating disorder. Neuropsychopharmacology (20I5) 40, I I63-II7I; doi:I0.1038/npp.2014.299; published online I0 December 2014
\end{abstract}

\section{INTRODUCTION}

Binge-eating disorder is one of most prevalent illnesses in the United States, affecting more than 10 million people (Kessler et al, 2013). The latest (fifth) edition of the Diagnostic and Statistical Manual of Mental Disorders has now designated binge-eating disorder as a psychiatric illness distinct from other eating disorders with a specific formal diagnosis. Core diagnostic criteria for binge-eating disorder include excessive consumption of food within brief periods of time, accompanied by loss of control, uncomfortable fullness, and intense feelings of disgust and embarrassment (APA, 2013). Growing evidence suggests that binge eating may result from neuroadaptative mechanisms in discrete areas of the brain that parallel drug and alcohol addiction (Avena et al, 2008; Corwin, 2006; Cottone et al,

*Correspondence: Dr P Cottone, Departments of Pharmacology and Psychiatry, Laboratory of Addictive Disorders, Boston University School of Medicine, 72 E Concord St, R-618, Boston, MA 02118, USA, Tel: +| 617638 5662, Fax: + 6176385668 ,

E-mail: cottone@bu.edu

Received 9 September 2014; revised 15 October 2014; accepted 5 November 2014; accepted article preview online 10 November 2014 2008b; Micioni Di Bonaventura et al, 2014; Parylak et al, 2012).

Addiction-related behaviors have been linked to impairments in the glutamatergic system in the nucleus accumbens (Kalivas and Volkow, 2011) and the N-methyl-Daspartic acid (NMDA) receptor has been proposed as a promising target for the treatment of a variety of addictive disorders (Gass and Olive, 2008). The NMDA receptor shows complex pharmacological properties and numerous classes of antagonists have been described (ie, competitive, noncompetitive, uncompetitive, allosteric (Traynelis et al, 2010)). Among the different classes of the NMDA channel blockers, uncompetitive antagonists are characterized by their ability to bind to the receptor when the pore is open, at an alternative site to that used by the agonist, therefore being left trapped inside the channel following its closure (Traynelis et al, 2010). A highly characterized uncompetitive antagonist of the NMDA receptor is memantine, a drug currently used in several countries as an Alzheimer's disease medication because of its neuroprotective properties (Yang et al, 2013). Notably, a large body of evidence shows that memantine reduces the reinforcing and rewarding effects of drugs of abuse (Hart et al, 2002; Hyytia et al, 1999; Popik 
et al, 2003; Sabino et al, 2013). Interestingly, a few studies have suggested the ability of memantine also to reduce excessive intake of palatable food (Bisaga et al, 2008; Foltin et al, 2008; Popik et al, 2011).

The aim of this study was, therefore, to systematically characterize the neuropsychopharmacological effects of memantine using a battery of tasks developed to evaluate different features of maladaptive feeding behavior induced by limiting access to highly palatable food in rats (Blasio et al, 2014; Cottone et al, 2012; Velazquez-Sanchez et al, 2014). In addition, this study was aimed at evaluating which area of the brain mediates the effects of memantine on excessive intake of palatable food.

Specifically, we determined whether systemic administration of memantine was able to prevent binge-like eating induced by either limited access to a highly palatable diet or by food restriction of the regular chow diet. We also characterized the effects of memantine on palatable food-seeking behavior, using a second-order schedule of reinforcement. Moreover, we determined whether memantine was able to block compulsive-like eating of palatable food, using a light/dark conflict test. We finally assessed the effects of memantine in reducing binge-like eating of a highly palatable diet following site-specific microinjection of the compound directly into the shell and core of the nucleus accumbens.

\section{MATERIALS AND METHODS}

\section{Subjects}

Male Wistar rats, 45-day-old upon arrival were given access to chow and water ad libitum. Procedures adhered to the National Institutes of Health Guide for the Care and Use of Laboratory Animals and were approved by Boston University Institutional Animal Care and Use Committee. For further details, see Supplementary file.

\section{Drugs}

For both systemic and site-specific studies, memantine hydrochloride was dissolved in isotonic filtered saline immediately before administration. For within-subject experiments, treatment days were separated by 1-3 intervening days until the variables returned to baseline. Doses, injection volume, suitability of the vehicle, and pretreatment times were based on previously published reports (Cottone et al, 2013; Sabino et al, 2013). For further details, see Supplementary file.

\section{Operant Binge-Like Eating Procedure in ad libitum-Fed Rats}

Training. Rats were habituated to the home-cage AIN-76A-based diet, hereafter referred to as 'Chow A/I' (5TUM diet formulated as $4-5 \mathrm{~g}$ extruded pellets, $65.5 \%$ (kcal) carbohydrate, $10.4 \%$ fat, $24.1 \%$ protein, $330 \mathrm{cal} / 100 \mathrm{~g}$; TestDiet, Richmond, IN). As previously described (Blasio et al, 2014; Cottone et al, 2012; Velazquez-Sanchez et al, 2014), animals were trained to self-administer food pellets (45-mg precision food pellets (Chow A/I)) and water $(100 \mu \mathrm{l})$ for $1 \mathrm{~h}$ a day, under a fixed-ratio 1 (FR1) schedule of reinforcement in the operant chambers. During instrumental training, food pellets were $45-\mathrm{mg}$ precision pellets, identical in composition to the diet that rats received in the home cage as $\sim 5 \mathrm{~g}$ extruded pellets, to ensure that food intake during operant sessions was not influenced by any hedonic factors, only by homeostatic needs.

Testing. After stable baseline of chow responding was achieved, half of the rats were assigned to a 'Chow' control group, in which the operant boxes dispensed the same 45mg chow pellets offered in the training phase, whereas the remaining rats were assigned to a 'Palatable' group, which received a nutritionally complete, chocolate-flavored, highsucrose $(50 \% \mathrm{kcal})$ AIN-76A-based diet, comparable in macronutrient composition and energy density to the chow diet (chocolate-flavored Formula 5TUL: 66.7\% (kcal) carbohydrate, $12.7 \%$ fat, $20.6 \%$ protein, metabolizable energy $344 \mathrm{cal} / 100 \mathrm{~g}$; formulated as $45-\mathrm{mg}$ precision food pellets; TestDiet). It was previously determined that this chocolate-flavored diet is strongly preferred by all rats (Cottone et al, 2008a, 2009). For further details, see Supplementary file.

Experiment 1: effects of systemic administration of memantine on operant binge-like eating. Chow and Palatable rats $(n=17)$, trained in the binge-like eating procedure, were injected with memantine $(0,1.25,2.5,5$, and $10 \mathrm{mg} / \mathrm{kg}$, i.p.), $30 \mathrm{~min}$ prior to the operant sessions, using a within-subject Latin-square design.

\section{High Rate of Responding for Chow A/I Induced by Food Restriction}

Rats were trained to acquire operant self-administration for the Chow A/I diet, whereas they were food restricted in their home cages. For this purpose, a specific amount of Chow A/I food was provided in the home-cages at the end of the operant self-administration sessions so that the total daily intake, including the food consumed during the self-administration session, equaled the $70 \%$ of a rat daily intake. Under these experimental conditions, the rate of responding for the Chow A/I diet of food-restricted rats was comparable to the rate of responding for the highly palatable sugary diet of ad libitum-fed Palatable rats. Rats were food restricted for 10 days before the drug treatment was initiated. For further details, see Supplementary file.

Experiment 2: effects of systemic administration of memantine on high rate of responding for Chow A/I induced by food restriction. Food-restricted rats $(n=10)$, trained in FR1 schedule for Chow A/I, were injected with memantine $(0,10 \mathrm{mg} / \mathrm{kg}$, i.p.) $30 \mathrm{~min}$ prior to their operant sessions, using a within-subject Latin-square design.

\section{Food-Seeking Behavior in ad libitum-Fed Rats: Second-Order Schedule of Reinforcement}

Food-seeking behavior under a second-order schedule of reinforcement is a procedure in which responding is maintained by the contingent presentation of food-paired stimuli that serve as conditioned reinforcers of instrumental 
behavior (Everitt and Robbins, 2000; Giuliano et al, 2012). In the second-order schedule of reinforcement (FI5(FR10:S)), every 10th active lever press (Fixed Ratio 10, FR10) resulted in a brief illumination of lights above both the active lever and the food magazine for $1 \mathrm{~s}$. Responses on the inactive lever had no programmed consequences but were recorded to assess discriminated responding and general levels of motor activity. Following the 10th active lever press, after a fixed interval of $5 \mathrm{~min}$ (FI5 min) had elapsed (Kelleher and Goldberg, 1977), 20 pellets (45-mg chow pellets for the Chow food group or 45-mg chocolate pellets for the Palatable food group) were delivered in the food magazine, both the active and inactive levers retracted, and the lights above both the active lever and the food magazine were presented for $20 \mathrm{~s}$ time out. During the FI interval, animals who pressed the active lever did not receive any pellets. After the time out, the lights above both the active lever and the food magazine turned off, and the two levers were again extended into the chamber. The second-order schedule of reinforcement session lasted $40 \mathrm{~min}$. For further details, see Supplementary file.

Experiment 3: effects of systemic administration of memantine on food-seeking behavior using a secondorder schedule of reinforcement. Chow and Palatable rats $(n=15)$, trained in the second-order schedule of reinforcement, were injected with memantine $(0,2.5,5$, and $10 \mathrm{mg} / \mathrm{kg}$, i.p.) 30 min prior to their operant sessions, using a withinsubject Latin-square design.

\section{Compulsive Eating of Palatable Food: Light/Dark Conflict Test}

In this test, a light/dark rectangular box was used, in which the aversive, bright compartment was illuminated by a 60 lux light. The dark compartment had an opaque cover and $\sim 0$ lux of light. The two compartments were connected by an open doorway, which allowed the subjects to move freely between the two. A shallow, metal cup containing a pre-weighed amount of the same food received during self-administration (45-mg chow pellets for the Chow food group or 45-mg chocolate pellets for the Palatable food group) was positioned in the center of the light compartment. On the test day, rats were placed into the light compartment, facing both the food cup and the doorway. Under normal, control conditions, eating behavior is typically suppressed when a rat is in the aversive, bright compartment; a significant increase in food intake in spite of the adverse conditions, as compared with control conditions, was operationalized as a construct of 'compulsive-like eating' (Cottone et al, 2012; Dore et al, 2014; Velazquez-Sanchez et al, 2014). The apparatus was cleaned with a water-dampened cloth after each subject. For further details, see Supplementary file.

Experiment 4: effects of systemic administration of memantine on compulsive-like eating. Chow and Palatable rats $(n=39)$ were injected with memantine $(0,2.5 \mathrm{mg} / \mathrm{kg}$, i.p. the lowest dose effective in reducing binge-like eating) $30 \mathrm{~min}$ prior to the 10 -min light/dark conflict test, using a betweensubjects design.
Intracranial Surgeries, Microinfusion Procedure, and Cannula Placement

Rats were stereotaxically implanted with bilateral, intracranial cannulas as described previously (Dore et al, 2013; Iemolo et al, 2013; Sabino et al, 2007). In brief, 24-gauge stainless steel guide cannulas were lowered bilaterally $1.5 \mathrm{~mm}$ above the nucleus accumbens (NAcc) shell or core. The cannula coordinates from the bregma used for the NAcc shell were: A/P $+1.06 \mathrm{~mm}, \mathrm{M} / \mathrm{L} \pm 0.75 \mathrm{~mm}, \mathrm{D} / \mathrm{V}$ $-5.5 \mathrm{~mm}$, flat skull. The cannula coordinates from the bregma used for the NAcc core were: $\mathrm{A} / \mathrm{P}+1.4 \mathrm{~mm}$, $\mathrm{M} / \mathrm{L} \pm 2.5 \mathrm{~mm}\left(6^{\circ}\right.$ angle), D/V $-5.5 \mathrm{~mm}$, flat skull. Stainless-steel dummy stylets maintained patency of the cannula. Thirty-three-gauge stainless-steel injector projecting $1.5 \mathrm{~mm}$ beyond the tip of the guide cannula were used; the injector was connected via $\mathrm{PE} 20$ tubing to a microsyringe driven by a microinfusion pump. Microinfusions were performed in $0.5 \mu \mathrm{l}$ volume per side delivered over $2 \mathrm{~min}$; injectors were left in place for 1 additional minute to minimize backflow. Subjects were anaesthetized and microinfused with India Ink $(0.5 \mu \mathrm{l} /$ side $)$. Brains were then flash-frozen and stored at $-80^{\circ} \mathrm{C}$. Coronal sections of $30 \mu \mathrm{m}$ were collected using a cryostat, and placements were verified under a microscope. Seven subjects $(n=2$ for NAcc shell, and $n=5$ for NAcc core) were excluded from analysis because of incorrect cannula placement. For further details, see Supplementary file.

Experiment 5: effects of administration of memantine into the NAcc shell on operant binge-like eating. Intra-NAcc shell cannulated rats $(n=11)$, trained in the binge-like eating procedure, were injected with memantine $(0,2.5,10$, and $20 \mu \mathrm{g} / \mathrm{side}$ ), immediately before their operant sessions, using a within-subject Latin-square design.

Experiment 6: effects of administration of memantine into the NAcc core on operant binge-like eating. Intra-NAcc core cannulated rats $(n=14)$, trained in the binge-like eating procedure, were injected with memantine $(0,2.5,10$, and $20 \mu \mathrm{g} / \mathrm{side}$ ), immediately before their operant sessions, using a within-subject Latin-square design.

\section{Statistical Analysis}

Parametrical data were analyzed by simple or factorial ANOVAs followed by Newman-Keuls tests. Statistical significance level was set at $\alpha \leqslant 0.05$.

\section{RESULTS}

\section{Experiment 1: Effects of Systemic Administration of Memantine on Operant Binge-Like Eating}

The Palatable food group consumed significantly more food compared with the Chow controls (diet, $\mathrm{F}_{(1,15)}=63.72$, $p \leqslant 0.001)$. Systemic memantine treatment selectively and dose-dependently reduced the binge-like eating of the Palatable food group in the operant task, without affecting intake of the control Chow food group (dose, $\mathrm{F}_{(4,60)}=5.93$, $p \leqslant 0.0001$; diet $\times$ dose, $\mathrm{F}_{(4,60)}=3.05, p \leqslant 0.05$; Figure $\left.1 \mathrm{a}\right)$. Post hoc analysis revealed that memantine significantly 
a

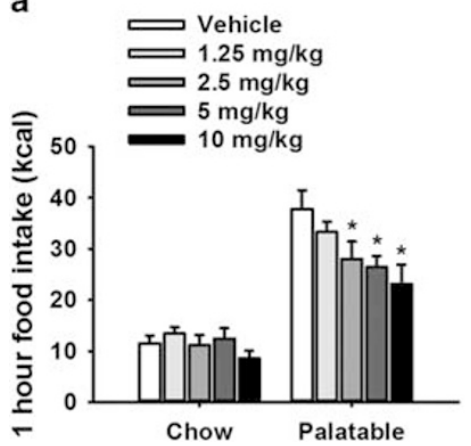

b

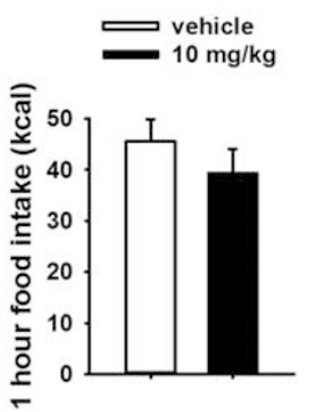

Figure I Effects of systemic treatment with memantine $(0,1.25,2.5,5$, $10 \mathrm{mg} / \mathrm{kg}$, i.p.) on $\mathrm{I}$ h food self-administration $(n=17)$ (a). Effects of systemic treatment with memantine $(0,10 \mathrm{mg} / \mathrm{kg}$, i.p.) on high rate of responding for Chow $\mathrm{A} / \mathrm{l}$ induced by food restriction $(n=10)$ (b). Data represent $\mathrm{M} \pm \mathrm{SEM}$. Symbols (*) denote significant difference from the vehicle-treated Palatable food group $p \leqslant 0.05$ (Newman-Keuls).

reduced binge-like eating when injected at the doses of 2.5, 5 , and $10 \mathrm{mg} / \mathrm{kg}$ compared with the vehicle-treated Palatable food group. When administered at the highest dose $(10 \mathrm{mg} /$ $\mathrm{kg}$ ), memantine treatment reduced binge-like eating in the Palatable food group by $39.0 \%(p=0.0001)$ and chow intake in the Chow food group by $25.6 \%(p=0.568)$ on average, compared with their respective vehicle-treated subjects. Water intake was not affected by the treatment in either the Chow or the Palatable group (dose, $\mathrm{F}_{(4,60)}=1.13$, n.s.; diet $\times$ dose, $\mathrm{F}_{(4,60)}=0.53$, n.s.; Table 1).

\section{Experiment 2: Effects of Systemic Administration of Memantine on High Rate of Responding for Chow A/I Induced by Food Restriction}

Responding for regular chow in food-restricted rats was comparable to responding for vehicle-treated palatable food in ad libitum-fed rats in the memantine systemic administration study $\left(t_{(16)}=1.32\right.$, n.s.). Systemic treatment with the highest dose of memantine effective in the binge-likeeating task $(10 \mathrm{mg} / \mathrm{kg}$, i.p.) had no effect on the high rate of responding for Chow $\mathrm{A} / \mathrm{I}$ in the operant FR1 food intake task in food-restricted rats $\left(t_{(9)}=1.27\right.$, n.s.; Figure $\left.1 \mathrm{~b}\right)$.

\section{Experiment 3: Effects of Systemic Administration of Memantine on Food-Seeking Behavior Under a Second- Order Schedule of Reinforcement.}

Analysis of the first interval. The analysis of the first (pre-ingestive) interval revealed that the Palatable food group showed significantly higher food-seeking responding compared with the Chow control rats (diet, $\mathrm{F}_{(1,13)}=9.34$, $p \leqslant 0.01$, Figure 2a, top). Memantine treatment blocked food-seeking behavior selectively and dose-dependently in the Palatable food group, without affecting responding in the control Chow food group (dose, $\mathrm{F}_{(3,39)}=4.70, p \leqslant 0.01$; diet $\times$ dose, $\left.F_{(3,39)}=3.04, p \leqslant 0.05\right)$. During the first interval, memantine treatment blocked the augmentation of foodseeking responding in the Palatable food group at all doses tested $(p=0.33, p=0.42$ and $p=0.95 v s$ the vehicle-treated Chow condition, at the $2.5,5$, and $10 \mathrm{mg} / \mathrm{kg}$ doses, respec-

Table I Effects of Memantine Administration on Water Intake

\begin{tabular}{lcc}
\hline Treatment & \multicolumn{2}{c}{ Water intake (ml) } \\
\cline { 2 - 3 } & Chow & Palatable \\
\hline Systemic & & \\
Vehicle & $5.48 \pm 1.09$ & $4.64 \pm 0.45$ \\
$1.25 \mathrm{mg} / \mathrm{kg}$ & $7.70 \pm 1.66$ & $8.80 \pm 0.93$ \\
$2.5 \mathrm{mg} / \mathrm{kg}$ & $12.27 \pm 6.82$ & $7.40 \pm 1.44$ \\
$5 \mathrm{mg} / \mathrm{kg}$ & $9.23 \pm 2.15$ & $8.06 \pm 1.32$ \\
$10 \mathrm{mg} / \mathrm{kg}$ & $5.28 \pm 2.85$ & $7.21 \pm 2.01$
\end{tabular}

$\begin{array}{lrr}\text { NAcc shell } & \\ \text { Vehicle } & 6.98 \pm 0.87 & 8.80 \pm 2.37 \\ 2.5 \mu \mathrm{g} & 7.44 \pm 1.21 & 10.38 \pm 3.23 \\ 10 \mu \mathrm{g} & 8.06 \pm 0.66 & 9.13 \pm 2.06 \\ 20 \mu \mathrm{g} & 6.88 \pm 1.05 & 9.98 \pm 1.76\end{array}$

\begin{tabular}{ccc} 
NAcc core & & \\
Vehicle & $8.89 \pm 1.63$ & $10.10 \pm 1.33$ \\
$2.5 \mu \mathrm{g}$ & $9.38 \pm 1.61$ & $13.66 \pm 1.83$ \\
$10 \mu \mathrm{g}$ & $8.78 \pm 1.96$ & $11.94 \pm 3.43$ \\
$20 \mu \mathrm{g}$ & $8.33 \pm 1.51$ & $8.78 \pm 1.27$ \\
\hline
\end{tabular}

Abbreviation: NAcc, nucleus accumbens.

Effects of systemic $(0,1.25,2.5,5,10 \mathrm{mg} / \mathrm{kg}$, i.p., $n=17)$, intra-NAcc shell, and intra-NAcc core administration of memantine $(0,2.5,10,20 \mu \mathrm{g} /$ side, $n=11$ and $n=14$, respectively) on water intake.

tively). Memantine did not affect responding in control at any of the doses tested $(p=0.94$, vehicle $v s 10 \mathrm{mg} / \mathrm{kg}$ treated Chow food group). During the first interval, inactive lever responding did not differ between groups (diet, $F_{(1,13)}=$ 0.25 , n.s., Figure $2 \mathrm{a}$, bottom), and it was not affected by drug treatment (dose, $\mathrm{F}_{(3,39)}=1.46$, n.s.; diet $\times$ dose, $\mathrm{F}_{(3,39)}=$ 1.15 , n.s.).

Analysis of the remaining intervals. The Palatable food group kept responding at a significantly higher rate compared with the Chow control rats during the remaining intervals of the second-order schedule of reinforcement (diet, $\mathrm{F}_{(1,13)}=12.75, p \leqslant 0.005$, Figure $2 \mathrm{~b}$, top). Intraperitoneal memantine treatment blocked food-seeking behavior selectively and dose-dependently in the Palatable food group, without affecting responding in the control Chow food group (Dose, $\mathrm{F}_{(3,39)}=6.80, p \leqslant 0.0001$; diet $\times$ dose, $\left.\mathrm{F}_{(3,39)}=2.79, p \leqslant 0.05\right)$. Memantine blocked the augmentation of food-seeking responding in the Palatable food group when injected at $10 \mathrm{mg} / \mathrm{kg}(p=0.72 v s$ vehicle-treated Chow condition). The same dose of memantine did not affect responding in control rats when compared with the vehicletreated Chow condition $(p=0.68)$. Inactive lever responding did not differ between groups (diet, $\mathrm{F}_{(1,13)}=0.05$, n.s., Figure 2b, bottom), and, although the two-way ANOVA detected an effect of treatment, post hoc analysis revealed no 
a

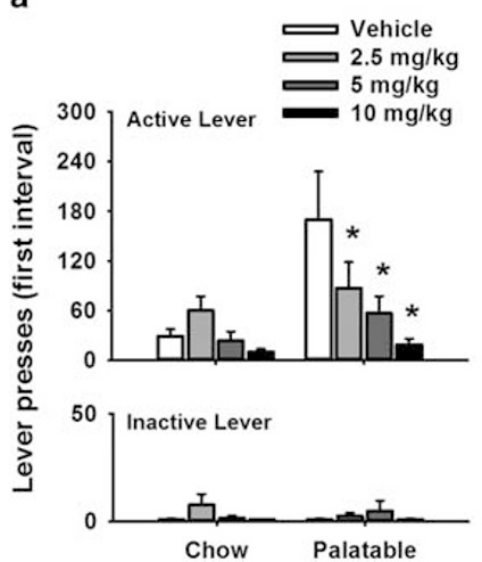

b

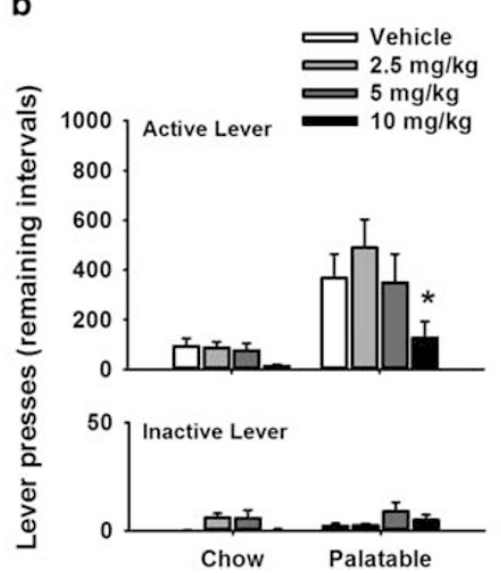

C

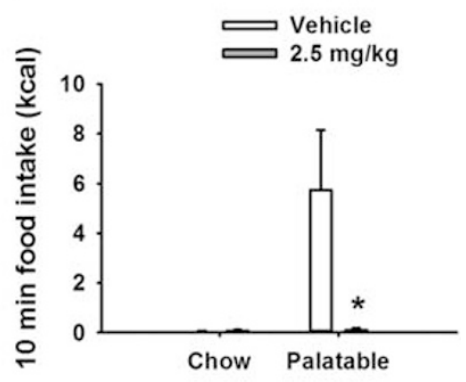

Figure 2 Effects of systemic treatment with memantine $(0,2.5,5,10 \mathrm{mg} / \mathrm{kg}$, i.p.) on the number of presses on the active and inactive levers in a secondorder schedule of reinforcement $(n=15)$ during the first interval (a) and during the remaining intervals of the experimental session. (b). Effects of systemic treatment with memantine $(0,2.5 \mathrm{mg} / \mathrm{kg}$, i.p.) on food intake during the light/dark conflict test (total $n=39)$ (c). Data represent $M \pm S E M$. Symbols (*) denote significant difference from the vehicle-treated Palatable food group $p \leqslant 0.05$ (Newman-Keuls).

differences among groups (dose, $\mathrm{F}_{(3,39)}=3.01, p \leqslant 0.05$; diet $\times$ dose, $\mathrm{F}_{(3,39)}=1.33$, n.s.).

\section{Experiment 4: Effects of Systemic Administration of Memantine on Compulsive-Like Eating}

The Palatable food group exhibited compulsive-like-eating behavior, consuming more food under vehicle conditions compared with the control Chow food group, although the food was placed in a bright, aversive compartment (diet, $\mathrm{F}_{(1,35)}=6.65, p \leqslant 0.02$, Figure $2 \mathrm{c}$ ). Memantine treatment fully and selectively blocked compulsive-like eating in the Palatable food group when the $2.5 \mathrm{mg} / \mathrm{kg}$ dose was administered (the lowest effective dose in the FR1 experiment) (diet, $\mathrm{F}_{(1,35)}=6.33, p \leqslant 0.02$; diet $\times$ dose $\mathrm{F}_{(1,35)}=6.48$, $p \leqslant 0.02)$.

\section{Experiment 5: Effects of Administration of Memantine} into the NAcc Shell on Operant Binge-Like Eating

The Palatable food group ate significantly more food than controls (diet, $\mathrm{F}_{(1,9)}=23.73 ; p \leqslant 0.001$, Figure 3a). IntraNAcc shell administration of memantine significantly reduced responding for food (dose, $\mathrm{F}_{(3,27)}=3.71, p \leqslant 0.05$ ). Although the two-way ANOVA did not detect an effect in the interaction between diet and dose $\left(\mathrm{F}_{(3,27)}=1.41, p=0.26\right)$, perhaps due to insufficient power, post hoc analysis revealed that both the middle and highest doses (10 and $20 \mu \mathrm{g}$ ) significantly reduced binge-like eating when compared with the vehicle-treated Palatable food group, without affecting control rats responding. When administered at the highest dose $(20 \mu \mathrm{g})$, memantine treatment reduced the intake of the Chow and Palatable food groups of a similar degree compared with their respective vehicle-treated subjects (37.1\% and $34.4 \%$, respectively). However, post hoc analysis revealed that the effect was significant only in the Palatable food group ( $p=0.766$ and $p=0.006$ in Chow and Palatable, respectively, $v s$ their respective vehicle-treated subjects). This discrepancy was due to a very high inconsistency in the reduction of the Chow group compared with the Palatable group (coefficient of variation for the reduction: 68\% vs $28 \%$ Chow vs Palatable group, respectively). Water intake was not affected by treatment in either the Chow or the Palatable group (dose, $\mathrm{F}_{(3,27)}=0.48$, n.s.; diet $\times$ dose, $\mathrm{F}_{(3,27)}=$ 0.61 , n.s., Table 1$)$.

\section{Experiment 6: Effects of Administration of Memantine into the NAcc Core on Operant Binge-Like Eating}

No effect on food intake in either the Chow or Palatable groups was observed when memantine was microinfused into the NAcc core (Figure 4a) A two-way ANOVA indicated a main effect of Diet $\left(\mathrm{F}_{(1,12)}=113.34 ; p \leqslant 0.0001\right)$. Neither a significant effect of dose $\left(\mathrm{F}_{(3,36)}=0.06\right.$; n.s. $)$ nor a significant interaction between the two factors (diet $\times$ dose, $\mathrm{F}_{(3,36)}=0.68$; n.s.) was observed. Water intake was not affected by intra NAcc core memantine treatment in either the Chow or the Palatable group (dose, $\mathrm{F}_{(3,36)}=1.75$, n.s.; diet $\times$ dose, $F_{(3,36)}=0.85$, n.s., Table 1$)$.

\section{DISCUSSION}

Memantine, systemically administered, reduced binge-like eating of a highly palatable, sucrose diet. The drug's effects were highly selective for the sugary diet as the intake of a regular chow diet remained unchanged. In addition, memantine treatment did not affect water intake, excluding the alternative interpretations that general behavioral suppression or motor impairment could be responsible for the observed reduction in food responding. Furthermore, when memantine's effects were tested on overeating of the regular chow diet induced by food restriction, the drug treatment was devoid of effect. Notably, it has been reported that a chronic, rather than acute, food restriction is necessary to induce adaptations in the reward system, which make rats more susceptible to the effects of drugs of abuse (Carr, 2007; D'Cunha et al, 2013). In this study, rats were food restricted for 10 days before the first within-subject injection of memantine and, consequently, we can exclude that the 


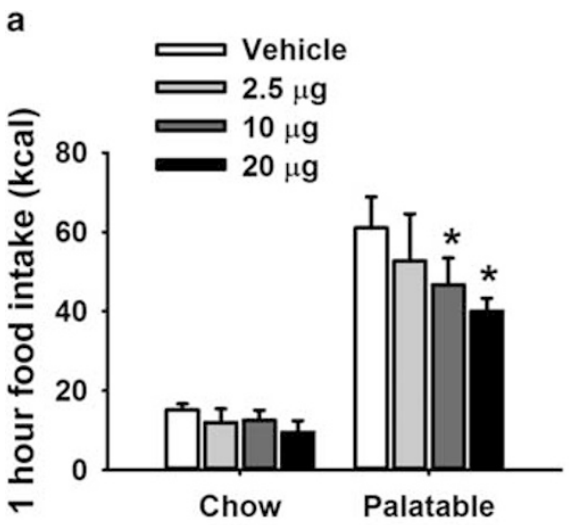

b
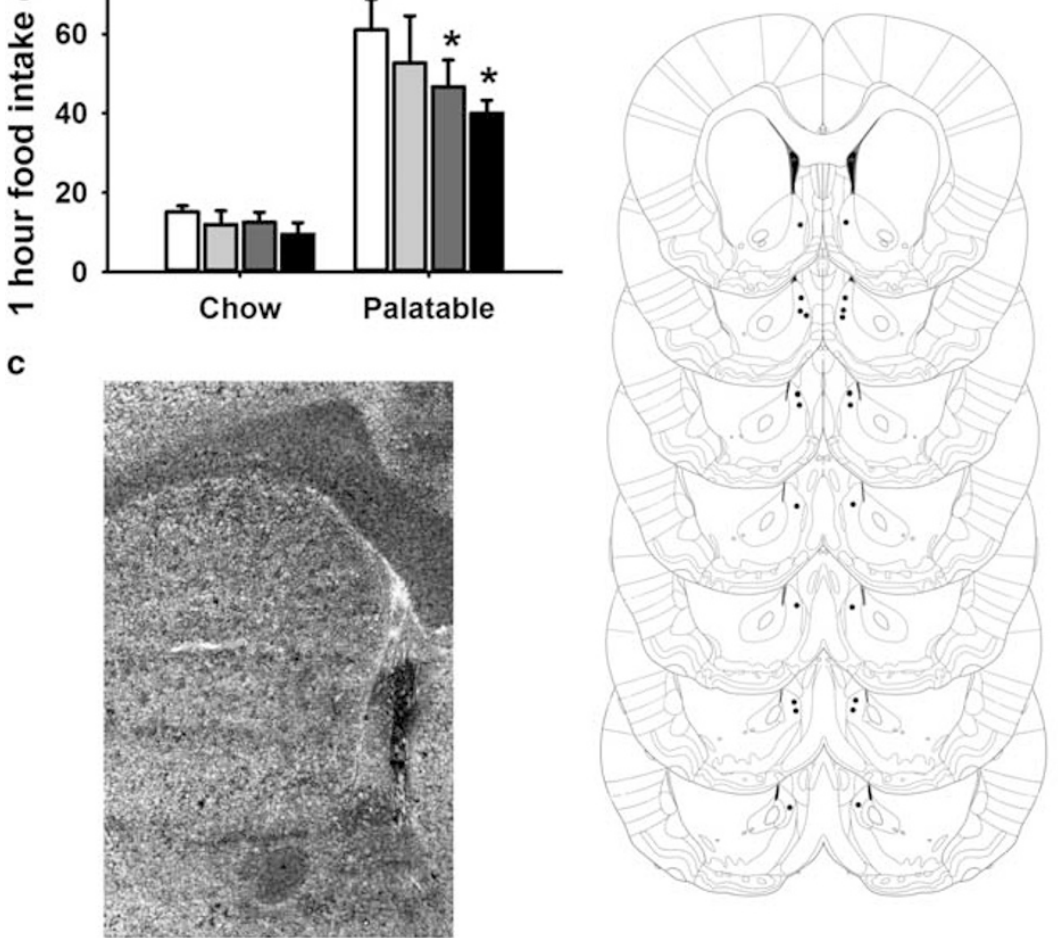

$0.72 \mathrm{~mm}$

$0.84 \mathrm{~mm}$

$1.20 \mathrm{~mm}$

$1.28 \mathrm{~mm}$

$1.56 \mathrm{~mm}$

$1.92 \mathrm{~mm}$

$2.04 \mathrm{~mm}$

Figure 3 Effects of intra-NAcc shell administration of memantine $(0,2.5,10,20 \mu \mathrm{g} /$ side $)$ on I h food self-administration $(n=1 \mathrm{I})$. Drawing of coronal rats' brain slices (a). Dots represent the injection sites in the NAcc shell included in the data analysis (b). Photomicrograph that shows a coronal section of the brain of a rat with a representative injection site in the NAcc shell (c). Data represent $M \pm$ SEM. Symbols (*) denote significant difference from the vehicletreated Palatable food group $p \leqslant 0.05$ (Newman-Keuls).

duration was not sufficiently long compared with what has been previously used (D'Cunha et al, 2013). Therefore, data from the food restriction experiment suggest that memantine's effects are specific for palatability induced behavioral processes and independent from high rates of response. More generally, these findings emphasize the difference between hedonic vs energy-homeostatic control of food intake and confirm the hypothesis that although food-related behavioral outcomes induced by palatability can be apparently similar to the ones observed following food restriction/deprivation, the two are governed by dissimilar neuroadaptive mechanisms (Corwin, 2006; Cottone et al, 2009; Cottone et al, 2012).

In this study, we used a food-seeking behavior task in ad libitum-fed rats using a second-order schedule of reinforcement, in which responding was maintained by contingent presentation of food-paired stimuli that served as conditioned reinforcers of instrumental behavior (Everitt and Robbins, 2000). Under the second-order schedule of reinforcement, bingeing rats showed a very high rate of responding, exhibiting an approximately sixfold increase in seeking behavior compared with control chow rats in the first interval and an approximately fourfold increase during the remaining intervals. Memantine treatment fully blocked palatable food-seeking behavior by reducing the number of active lever presses. Interestingly, memantine was more potent in suppressing seeking behavior of palatable food during the first interval, the only one that occurs before food ingestion. The marked reduction in responding was not attributable to nonspecific effects as neither responding for regular chow diet nor the number of inactive lever responses was reduced by the drug. These results, therefore, suggest that memantine blocks the incentive mechanisms controlling food seeking, and this aspect is of particular relevance as palatable food-associated environmental cues exert a powerful control over feeding behavior, which can override energy-homeostasis signals (Everitt and Robbins, 2000; Giuliano et al, 2012). Our findings are in contrast with the results shown by Bisaga et al, 2008, in which authors showed that memantine treatment did not decrease candyseeking behavior. A major difference between the two foodseeking tasks, which may explain the discrepancy, is that the procedure used by Bisaga and colleagues lasted $24 \mathrm{~h} /$ day, and therefore monkeys had to go through the appetitive phase to consume food during the day, whereas in the present study, the session lasted only $40 \mathrm{~min} /$ day and rats had free access to food in the home cages. In addition, the authors in the previous study investigated the latency to the first candy meal, whereas we are measuring the number of responses on the active lever. For all these reasons, a direct comparison between the two studies is problematic.

As previously shown (Cottone et al, 2012; Velazquez-Sanchez et al, 2014), bingeing rats exhibited compulsive-eating behavior, 
a

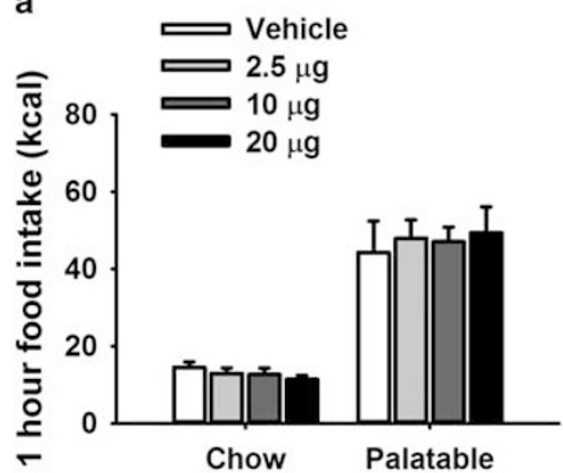

b

C
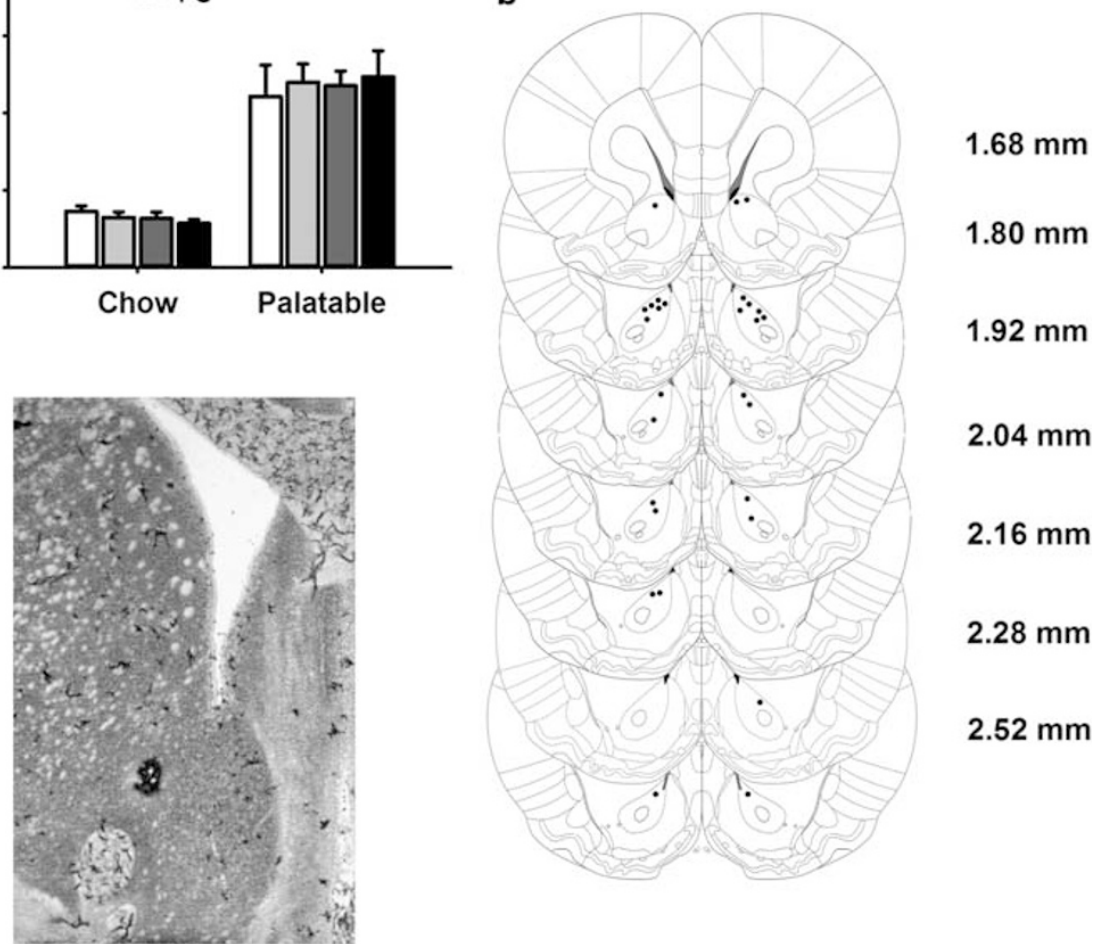

$2.04 \mathrm{~mm}$

$2.16 \mathrm{~mm}$

$2.28 \mathrm{~mm}$

$2.52 \mathrm{~mm}$

Figure 4 Effects of intra-NAcc core administration of memantine $(0,2.5,10,20 \mu \mathrm{g} /$ side) on I h food self-administration $(n=14)$. Drawing of coronal rats' brain slices (a). Dots represent the injection sites in the NAcc shell included in the data analysis (b). Photomicrograph that shows a coronal section of the brain of a rat with a representative injection site in the NAcc core (c). Data represent $M \pm S E M$.

as measured by highly palatable food consumption that was resistant to disruption by aversive conditions. Indeed, rats with a history of daily $1 \mathrm{~h}$ access to the highly palatable diet, consumed $\sim 173$ times more food than Chow control rats, when food was placed in the bright, aversive compartment of a light/dark box. Memantine pretreatment fully blocked compulsive eating, bringing the intake of the Palatable food group to the control Chow level. We can confidently exclude that the effect of drug treatment on the light/dark conflict test was influenced by a potential anxiogenic effect, as memantine has been shown to exert either no effect or anxiolytic effects (Koltunowska et al, 2013; Minkeviciene et al, 2008).

Although the effects of memantine on binge-like eating may be counterintuitive when compared with its capability of increasing impulsive behavior (Cottone et al, 2013; Smith et al, 2011), they are in agreement with its ability to decrease reinforcement of drugs of abuse as well as alcohol (Blokhina et al, 2005; Hyytia et al, 1999; Sabino et al, 2013; Semenova et $a l, 1999)$. Interestingly, the same paradoxical effect is shared by other NMDA uncompetitive antagonists; indeed, both dizocilpine and ketamine have been shown to increase impulsive behavior in different tasks (Cottone et al, 2013; Nemeth et al, 2010; Paine and Carlezon, 2009), but reduce reinforcement of drug of abuse and alcohol (Hyytia et al, 1999; Sabino et al, 2013; Schenk et al, 1993).

Notably, we here provide evidence that the NAcc shell, but not the core, is implicated in the effects of memantine on binge-like eating of a highly palatable, sucrose diet. Indeed, microinfusion of memantine into the NAcc shell was able to decrease palatable food responding without affecting chow or water responding. To the best of our knowledge, no previous studies have investigated the effects of the brain site-specific administration of memantine on food-related behavior. Few studies have investigated the effects of other uncompetitive antagonists on feeding behavior, although it is critical to remember that the distinctive binding profile of memantine makes this drug pharmacologically unique and different from any other antagonists of the same class (Traynelis et al, 2010). The lack of effect on regular chow intake following microinfusion with memantine into the NAcc shell confirms the previous observation that the uncompetitive NMDA receptor antagonist dizocilpine microinfused into the same area did not affect the intake of a regular chow diet (Maldonado-Irizarry et al, 1995). Another study has reported that MK-801 did not affect regular chow intake when injected within rostral subregions of the NAcc shell, but decreased it only at the highest dose when microinfused within caudal regions of the same area (Reynolds and Berridge, 2003). The observed effects, therefore, suggest that the glutamate/NMDA receptor system within the NAcs-shell is recruited in binge-like eating rats. Activity of the NAcc is greatly modulated by glutamatergic projections that originate in prefrontocortical regions of the brain, including prefrontal and 
anterior cingulate cortices (Brog et al, 1993; McGeorge and Faull, 1989; Zahm and Brog, 1992). Chronic drug use causes neuroadaptations in corticofugal projections to the NAcc, which are hypothesized to be responsible of impaired control over drugs (Kalivas et al, 2005). Interestingly, we have previously demonstrated that rats undergoing the binge-like eating procedure used here exhibit dysfunctions in the prefrontal and anterior cingulate cortices (Blasio et al, 2014; Cottone et al, 2012). Therefore, we hypothesize that dysfunctions in cortico-accumbal glutamatergic projections may mediate the maladaptive behavioral phenotype in rats intermittently exposed to the highly palatable diet.

\section{Therapeutic Implications}

The present study shows that the uncompetitive NMDA receptor antagonist memantine, a well-tolerated drug marketed for the treatment of Alzheimer's disease (Yang et al, 2013), is effective in reducing rodents' palatable foodinduced behavioral adaptations, which mimic the characteristic symptomatology observed in binge-eating disorder (ie, excessive food intake, heightened food-seeking behavior, and compulsive eating). Memantine reduced bingelike eating of a sucrose diet, an effect which was not a consequence of the high rate of responding, but which was, instead, dependent on the hedonic properties of the food. When administered in individuals affected by binge-eating disorder, memantine has been demonstrated to be effective in reducing the frequency of binge days and episodes, severity of illness, disinhibition and disability (Brennan et al, 2008; Hermanussen and Tresguerres, 2005). In the present study, memantine fully blocked palatable foodinduced seeking behavior, revealing the importance of this drug treatment not only for the consummatory aspect of binge eating, but also for the salient environmental stimuli which can trigger a binge-eating episode ( $\mathrm{Ng}$ and Davis, 2013). Remarkably, memantine treatment fully blocked the compulsivity associated with the intake of the highly palatable food, confirming the potential therapeutic role of this drug in curing aspects of compulsiveness in humans (Ghaleiha et al, 2013; Grant et al, 2012; Hart et al, 2002). Finally, our results provide evidence of the neuroanatomical site of action for the effects of memantine, as drug treatment reduced binge-like eating when microinfused into the shell, but not the core, of the NAcc. Our results, therefore, substantiate the use of memantine as a potential pharmacological treatment for binge-eating disorder.

\section{FUNDING AND DISCLOSURE}

This publication was made possible by grant numbers DA030425, MH091945, and MH093650 from the National Institute on Drug Abuse (NIDA) and the National Institute of Mental Health (NIMH), by the Peter Paul Career Development Professorship (to PC), the McManus Charitable Trust (to VS) and by Boston University's Undergraduate Research Opportunities Program (UROP). Its contents are solely the responsibility of the authors and do not necessarily represent the official views of the National Institutes of Health. The authors declare no conflict of interest.

\section{ACKNOWLEDGEMENTS}

We thank Stephen St Cyr and Diane Tang for technical assistance.

\section{REFERENCES}

APA (2013). Diagnostic and Statistical Manual of Mental Disorders. 5th edn. American Psychiatric Association.

Avena NM, Rada P, Hoebel BG (2008). Evidence for sugar addiction: Behavioral and neurochemical effects of intermittent, excessive sugar intake. Neurosci Biobehav Rev 32: 20-39.

Bisaga A, Danysz W, Foltin RW (2008). Antagonism of glutamatergic NMDA and mGluR5 receptors decreases consumption of food in baboon model of binge-eating disorder. Eur Neuropsychopharmacol 18: 794-802.

Blasio A, Steardo L, Sabino V, Cottone P (2014). Opioid system in the medial prefrontal cortex mediates binge-like eating. Addict Biol 19: 652-662.

Blokhina EA, Kashkin VA, Zvartau EE, Danysz W, Bespalov AY (2005). Effects of nicotinic and NMDA receptor channel blockers on intravenous cocaine and nicotine self-administration in mice. Eur Neuropsychopharmacol 15: 219-225.

Brennan BP, Roberts JL, Fogarty KV, Reynolds KA, Jonas JM, Hudson JI (2008). Memantine in the treatment of binge eating disorder: an open-label, prospective trial. Int J Eat Disord 41: 520-526.

Brog JS, Salyapongse A, Deutch AY, Zahm DS (1993). The patterns of afferent innervation of the core and shell in the "accumbens" part of the rat ventral striatum: immunohistochemical detection of retrogradely transported fluoro-gold. J Comp Neurol 338: 255-278.

Carr KD (2007). Chronic food restriction: enhancing effects on drug reward and striatal cell signaling. Physiol Behav 91: 459-472.

Corwin RL (2006). Bingeing rats: a model of intermittent excessive behavior? Appetite 46: 11-15.

Cottone P, Iemolo A, Narayan AR, Kwak J, Momaney D, Sabino V (2013). The uncompetitive NMDA receptor antagonists ketamine and memantine preferentially increase the choice for a small, immediate reward in low-impulsive rats. Psychopharmacology (Berl) 226: 127-138.

Cottone P, Sabino V, Steardo L, Zorrilla EP (2008a). Intermittent access to preferred food reduces the reinforcing efficacy of chow in rats. Am J Physiol 295: R1066-R1076.

Cottone P, Sabino V, Steardo L, Zorrilla EP (2008b). Opioiddependent anticipatory negative contrast and binge-like eating in rats with limited access to highly preferred food. Neuropsychopharmacology 33: 524-535.

Cottone P, Sabino V, Steardo L, Zorrilla EP (2009). Consummatory, anxiety-related and metabolic adaptations in female rats with alternating access to preferred food. Psychoneuroendocrinology 34: 38-49.

Cottone P, Wang X, Park JW, Valenza M, Blasio A, Kwak J et al (2012). Antagonism of sigma-1 receptors blocks compulsive-like eating. Neuropsychopharmacology 37: 2593-2604.

D'Cunha TM, Sedki F, Macri J, Casola C, Shalev U (2013). The effects of chronic food restriction on cue-induced heroin seeking in abstinent male rats. Psychopharmacology (Berl) 225: 241-250.

Dore R, Iemolo A, Smith KL, Wang X, Cottone P, Sabino V (2013). CRF mediates the anxiogenic and anti-rewarding, but not the anorectic effects of PACAP. Neuropsychopharmacology 38: 2160-2169.

Dore R, Valenza M, Wang X, Rice KC, Sabino V, Cottone P (2014). The inverse agonist of CB1 receptor SR141716 blocks compulsive eating of palatable food. Addict Biol 19: 849-861.

Everitt BJ, Robbins TW (2000). Second-order schedules of drug reinforcement in rats and monkeys: measurement of reinforcing efficacy and drug-seeking behaviour. Psychopharmacology (Berl) 153: $17-30$. 
Foltin RW, Danysz W, Bisaga A (2008). A novel procedure for assessing the effects of drugs on satiation in baboons: effects of memantine and dexfenfluramine. Psychopharmacology (Berl) 199: 583-592.

Gass JT, Olive MF (2008). Glutamatergic substrates of drug addiction and alcoholism. Biochem Pharmacol 75: 218-265.

Ghaleiha A, Entezari N, Modabbernia A, Najand B, Askari N, Tabrizi $\mathrm{M}$ et al (2013). Memantine add-on in moderate to severe obsessive-compulsive disorder: randomized double-blind placebo-controlled study. J Psychiatr Res 47: 175-180.

Giuliano C, Robbins TW, Nathan PJ, Bullmore ET, Everitt BJ (2012). Inhibition of opioid transmission at the mu-opioid receptor prevents both food seeking and binge-like eating. Neuropsychopharmacology 37: 2643-2652.

Grant JE, Odlaug BL, Mooney M, O’Brien R, Kim SW (2012). Openlabel pilot study of memantine in the treatment of compulsive buying. Ann Clin Psychiatry 24: 119-126.

Hart CL, Haney M, Foltin RW, Fischman MW (2002). Effects of the NMDA antagonist memantine on human methamphetamine discrimination. Psychopharmacology (Berl) 164: 376-384.

Hermanussen M, Tresguerres JA (2005). A new anti-obesity drug treatment: first clinical evidence that, antagonising glutamategated $\mathrm{Ca} 2+$ ion channels with memantine normalises bingeeating disorders. Econ Hum Biol 3: 329-337.

Hyytia P, Backstrom P, Liljequist S (1999). Site-specific NMDA receptor antagonists produce differential effects on cocaine selfadministration in rats. Eur J Pharmacol 378: 9-16.

Iemolo A, Blasio A, St Cyr SA, Jiang F, Rice KC, Sabino V et al (2013). CRF-CRF1 receptor system in the central and basolateral nuclei of the amygdala differentially mediates excessive eating of palatable food. Neuropsychopharmacology 38: 2456-2466.

Kalivas PW, Volkow N, Seamans J (2005). Unmanageable motivation in addiction: a pathology in prefrontal-accumbens glutamate transmission. Neuron 45: 647-650.

Kalivas PW, Volkow ND (2011). New medications for drug addiction hiding in glutamatergic neuroplasticity. Mol Psychiatry 16: 974-986.

Kelleher RT, Goldberg SR (1977). Fixed-interval responding under second-order schedules of food presentation or cocaine injection. J Exp Anal Behav 28: 221-231.

Kessler RC, Berglund PA, Chiu WT, Deitz AC, Hudson JI, Shahly V et al (2013). The prevalence and correlates of binge eating disorder in the world health organization world mental health surveys. Biol Psychiatry 73: 904-914.

Koltunowska D, Gibula-Bruzda E, Kotlinska JH (2013). The influence of ionotropic and metabotropic glutamate receptor ligands on anxiety-like effect of amphetamine withdrawal in rats. Prog Neuropsychopharmacol Biol Psychiatry 45: 242-249.

Maldonado-Irizarry CS, Swanson CJ, Kelley AE (1995). Glutamate receptors in the nucleus accumbens shell control feeding behavior via the lateral hypothalamus. J Neurosci 15: 6779-6788.

McGeorge AJ, Faull RL (1989). The organization of the projection from the cerebral cortex to the striatum in the rat. Neuroscience 29: 503-537.

Micioni Di Bonaventura MV, Ciccocioppo R, Romano A, Bossert JM, Rice KC, Ubaldi M et al (2014). Role of bed nucleus of the stria terminalis corticotrophin-releasing factor receptors in frustration stress-induced binge-like palatable food consumption in female rats with a history of food restriction. J Neurosci 34: 11316-11324.
Minkeviciene R, Banerjee P, Tanila H (2008). Cognition-enhancing and anxiolytic effects of memantine. Neuropharmacology 54: 1079-1085.

Nemeth CL, Paine TA, Rittiner JE, Beguin C, Carroll FI, Roth BL et al (2010). Role of kappa-opioid receptors in the effects of salvinorin A and ketamine on attention in rats. Psychopharmacology (Berl) 210: 263-274.

$\mathrm{Ng}$ L, Davis C (2013). Cravings and food consumption in Binge Eating Disorder. Eat Behav 14: 472-475.

Paine TA, Carlezon WA Jr (2009). Effects of antipsychotic drugs on MK-801-induced attentional and motivational deficits in rats. Neuropharmacology 56: 788-797.

Parylak SL, Cottone P, Sabino V, Rice KC, Zorrilla EP (2012). Effects of $\mathrm{CB} 1$ and $\mathrm{CRF} 1$ receptor antagonists on binge-like eating in rats with limited access to a sweet fat diet: lack of withdrawal-like responses. Physiol Behav 107: 231-242.

Popik P, Kos T, Zhang Y, Bisaga A (2011). Memantine reduces consumption of highly palatable food in a rat model of binge eating. Amino Acids 40: 477-485.

Popik P, Wrobel M, Rygula R, Bisaga A, Bespalov AY (2003). Effects of memantine, an NMDA receptor antagonist, on place preference conditioned with drug and nondrug reinforcers in mice. Behav Pharmacol 14: 237-244.

Reynolds SM, Berridge KC (2003). Glutamate motivational ensembles in nucleus accumbens: rostrocaudal shell gradients of fear and feeding. Eur J Neurosci 17: 2187-2200.

Sabino V, Cottone P, Steardo L, Schmidhammer H, Zorrilla EP (2007). 14-Methoxymetopon, a highly potent mu opioid agonist, biphasically affects ethanol intake in Sardinian alcohol-preferring rats. Psychopharmacology (Berl) 192: 537-546.

Sabino V, Narayan AR, Zeric T, Steardo L, Cottone P (2013). mTOR activation is required for the anti-alcohol effect of ketamine, but not memantine, in alcohol-preferring rats. Behav Brain Res 247: 9-16.

Schenk S, Valadez A, Worley CM, McNamara C (1993). Blockade of the acquisition of cocaine self-administration by the NMDA antagonist MK-801 (dizocilpine). Behav Pharmacol 4: 652-659.

Semenova S, Danysz W, Bespalov A (1999). Low-affinity NMDA receptor channel blockers inhibit acquisition of intravenous morphine self-administration in naive mice. Eur J Pharmacol 378: $1-8$.

Smith JW, Gastambide F, Gilmour G, Dix S, Foss J, Lloyd K et al (2011). A comparison of the effects of ketamine and phencyclidine with other antagonists of the NMDA receptor in rodent assays of attention and working memory. Psychopharmacology (Berl) 217: 255-269.

Traynelis SF, Wollmuth LP, McBain CJ, Menniti FS, Vance KM, Ogden KK et al (2010). Glutamate receptor ion channels: structure, regulation, and function. Pharmacol Rev 62: 405-496.

Velazquez-Sanchez C, Ferragud A, Moore CF, Everitt BJ, Sabino V, Cottone $\mathrm{P}$ (2014). High trait impulsivity predicts food addictionlike behavior in the rat. Neuropsychopharmacology 39: 24632472.

Yang Z, Zhou X, Zhang Q (2013). Effectiveness and safety of memantine treatment for Alzheimer's disease. J Alzheimers Dis 36: $445-458$

Zahm DS, Brog JS (1992). On the significance of subterritories in the "accumbens" part of the rat ventral striatum. Neuroscience 50: 751-767.

Supplementary Information accompanies the paper on the Neuropsychopharmacology website (http://www.nature.com/npp) 